\title{
Determination of Solar Energy for the Bioclimatic Design of Housing in the City of Juliaca Peru
}

\section{Elmer Rodrigo Aquino Larico}

Department of Engineering in Renewable Energies, National University of Juliaca, Juliaca, Peru

Email address:

rodrigo19_x@hotmail.com

\section{To cite this article:}

Elmer Rodrigo Aquino Larico. Determination of Solar Energy for the Bioclimatic Design of Housing in the City of Juliaca Peru. International Journal of Energy and Environmental Science. Vol. 4, No. 1, 2019, pp. 1-9. doi: 10.11648/j.ijees.20190401.11

Received: November 9, 2018; Accepted: March 4, 2019; Published: March 28, 2019

\begin{abstract}
Solar energy is an inexhaustible source, clean and does not pollute the environment being a resource that can be used. The objective of this research work is to determine solar energy for the bioclimatic design of houses in the city of Juliaca for two systems: solar photovoltaic for the generation of electric power and solar thermal for water heating. In the development of this project the daily measurement for three months of the solar irradiation was made with a solar measuring instrument MAC-SOLAR Solarimeter SLM018c-2, where the Peak Sun Hours (HSP) were determined with the methodology of negative asymmetric distribution of $6.632 \mathrm{kwh} / \mathrm{m}^{2} /$ day and an average irradiation value of $1110.04 \mathrm{w} / \mathrm{m}^{2}$ in the city of Juliaca, with an optimum time interval from 9:00 am to 3:00 pm irradiation during the day, which has allowed modeling the behavior of solar energy for the design of a photovoltaic and thermal solar system; In addition, an experimental radiant floor module has been built in a bioclimatic room, which by recirculation of hot water through the floor reaches an average temperature of $20.93^{\circ} \mathrm{C}$ from 6:00 am to 9:00 pm, being within the zone of comfort of the Givoni Psychometric Diagram and the Peruvian Technical Standard (NTP).
\end{abstract}

Keywords: Bioclimatic, Solar, Photovoltaic, Irradiation, Thermal and Radiant Floor

\section{Introduction}

The present investigation refers to the subject of the determination of solar energy for the bioclimatic design of houses in the city of Juliaca, where research is carried out regarding the cold problems in the city of Juliaca, and the bioclimatic design of homes with systems photovoltaic and thermal in the city of Juliaca. Addressing issues of photovoltaic and thermal solar energy, solar irradiation, solar tilt angle, hour angle, bioclimatic design and underfloor heating; to then continue with the methodology of the investigation using the information obtained during three months of research of solar irradiation and temperature, taking it to a statistical analysis of negative asymmetric distribution to approximate the maximum solar HSP curve and obtaining a mathematical model. With these results are applied in the experimental construction of a photovoltaic and thermal solar system, in addition to implementing an experimental room in the city of Juliaca where a radiant floor is installed achieving adequate comfort in an experimental room in the city of Juliaca.

Renewable energies in the world represent more than $20 \%$, solar energy being the fourth based on the principle of the photoelectric effect for the generation of electricity and the thermosyphon effect for the heating of water, this energy would represent in 2050 between the 8 and $15 \%$ of electricity worldwide. Not being a short and medium term complete alternative [1].

In Belgium in a study carried out on 1500 residential photovoltaic solar installations to evaluate the energy production in terms of solar irradiation, where the measurement of solar irradiation was carried out in the network of radiometric stations controlled by the Royal Meteorological Institute of Belgium; the study concludes that the efficiency of photovoltaic solar installations depends on the climatological factors, the density, the horizontal and vertical orientation of the solar panels, when there is low solar elevation, the author mentions that the method does not produce a valid estimate in 
Alimeninas facilities [2]. Using the methodology of the Geographic Information System (GIS) in the province of Salta Argentina, to determine solar irradiation with data from satellite applications of Terrestrial Surface Analysis (LSA) on a daily, monthly and annual basis for seven years for the taking of decisions on renewable energy policies; GIS was also used in urban-scale buildings in the provinces of Italy to assess solar irradiation, considering the international standard (ISO 13790: 2008) proposed by the Italian standard using the methodology of topographic maps or digital land models. superficial ones that can be processed by the (GIS) [3, 4]. To predict the solar irradiation of an experimental $1 \mathrm{Mw}$ solar power plant in Odisha, India; We developed a Robust Extreme Learning Machine based on a low range kernel, with ranges of $15 \mathrm{~min}, 1$ hour and 1 day, based on the method of decomposition in empirical mode, where solar irradiation was determined in diverse climatic conditions, comparing these results with the solar power plant located in Florida [5]. Comparing different existing methodologies of calculation principles for the determination of operating parameters in solar panels such as: Power in vacuum, with load, voltage in vacuum, with load, current with load, in short circuit and others; the author compares this methodology with the quantum method of quantity of energy loss to take it to a simulation and evaluate the effect of solar irradiation and temperature on the performance of photovoltaic solar panels to plot the maximum power point with various tests [6]. In a study conducted to determine solar irradiation using various weather stations of the Republic of Croatia to then compare them with satellite images and measurements on the land surface by private stations, reaching results that vary from $(3-24) \%$ according to the Weather Station; these results can be used for the design of photovoltaic solar power plants by reducing energy imports in Croatia, guaranteeing a sustainable environmental development [7]. Using the methodology for stochastic persistence, without the need to use historical data, this method is based on the use of a few variables measured in a few hours, to process this information in an automatic statistical analysis or selflearning to persist in the processing of data in an additive or multiplicative way, thus determining the global solar irradiation, validating these results with the experimental measurements made in Ajaccio - France and Tilos Greece; being an efficient and fast way to determine solar irradiation [8].

In the modern world, buildings represent $40 \%$ of the total energy consumed and represent $30 \%$ of polluting gases contributing to the greenhouse effect, which is why it is necessary to use energy efficient alternatives such as renewable energy for heating, cooling and hot water, reducing the use of fossil fuels for power generation [9].

It is important to mention that [10], developed a work entitled: Analysis of performance and energy benefits of a desiccant based solar assisted trigeneration system in a building; where a large-scale solar trigeneration system with solar desiccant air conditioning has been installed in a public center in Australia. For the period of analysis from August 2012 to July 2013, the hot water before solar domestic heating has provided in approximately total $47600 \mathrm{kwh}$ of energy, saving $5000 \mathrm{~m}^{3}$ of gas. This represents $21 \%$ of the total energy use for domestic hot water. In addition to the housing built for low-income people in the city of Mexicali for being an area with a very high average temperature of $40^{\circ} \mathrm{C}$ in the summer, adopting the technology of cross ventilation with the use of renewable energy [11]. In research conducted in Thailand in a bioclimatic housing on the roof and wall reducing the temperature of $(1-2)^{\circ} \mathrm{C}$ using the double layer solar chimney [12]. Bioclimatic design is a sustainable concept that considers the climate and the relationship with human beings in a means of preserving the environment [13]. Bioclimatic design strategies have been proposed for decades, on a qualitative basis, because a quantitative approach, inescapably based on dynamic measurements or simulations, was too expansive and complex, if the simulation evolved considerably, in recent years, in terms of speed, cost and diffusion of available tools, its use is still complicated by the administration of a large amount of data per hour [14]. In a project carried out to measure the solar irradiation with the voltage, current and temperature parameters with a photovoltaic module using an Integral Proportional (PI) controller on a dSpace 1104 plate [15].

In relation to this work [16], entitled: East to West - The optimum angle of inclination and the orientation of the photovoltaic panels from a perspective of the electrical system; the compensation between energy losses and possible reductions in system costs for status $Q$ and to increase PV actions in the system is evaluated. The wholesale market value of the reductions in PV and potential fuel and $\mathrm{CO} 2$ cost through the implementation of PV for various tilt angles and orientations in 23 regions of Austria and Germany was analyzed using data on the prices of the electricity and the use of an electricity dispatch model for large PV operations.

Considering solar energy as an effective, economical and safe energy resource, the Qinghai-Tibet Plateau, the Inner Mongolia Plateau and other plateau areas that are rich in solar energy resources have the potential to develop and utilize solar energy resources on a large scale. In addition, solar thermal and photovoltaic technologies have been widely applied in buildings due to the rapid development of solar energy technologies and the gradual reduction of the cost of solar energy equipment. The use of solar energy resources in the study area is efficiently integrated in recent years [17].

In the last decade, Spain was one of the countries that most actively promoted the generation of electricity with renewable energy sources. This positioned the country, in 2008 and 2009, as the first in solar thermal capacity in the world (and fourth in wind power) and one of the main 
producers of photovoltaic energy. During this time, the expansion of these technologies was driven by quite favorable regulations, which included a series of subsidies for investments and a system for the stability of sale prices. However, government budget deficits, together with the deficit in the electricity sector, caused a progressive reversal of this type of policies that had previously been the motors of renewable energies [18]. Finally, in relation to the latter, we mention [19], with his work entitled: Energy Perspectives of Spain: A review of the photovoltaic potential and the export of energy; where Spain has made efforts in support and development of solar energy for the generation of electrical energy in a sustainable manner to meet the future of energy and its related environmental challenges. However, it is in fact destabilizing and without a preceding economic crisis, which has prompted the government to block photovoltaic incentives and slow down the growth of the solar energy sector.

The increasing use of solar energy in the world thanks to the Standard Measurement Conditions (CEM), we observe an average solar irradiation in Malaysia of $1004 \mathrm{w}$ / $\mathrm{m} 2$ within the Atmosphere [20], observing in Latin America in the country of Uruguay a solar irradiation of $1002 \mathrm{w} / \mathrm{m}^{2}$ [21] and in the research that was done in northern Mexico with a maximum solar irradiation of 5 $\mathrm{kwh} / \mathrm{m}^{2} /$ day [22]. To estimate the annual mean of daily solar irradiation in mountainous plateau regions, observed data from 15 radiation stations were used to validate different methods of empirical estimation on the Tibetan plateau, to achieve better performance, the Ångström model was improved using the altitude and pressure of water vapor as main factors [23]. To determine the solar irradiation without using very expensive resources, a south-facing thermal box inclined at $26.5^{\circ}$ from the horizontal was used for the measurements of solar radiation, in addition, the recorded solar radiation data was recovered for the location of the study and were used to develop a fourth order derived polynomial empirical correlation related the fuzzy fraction with the clarity index, the components of diffuse and reflected solar radiation were essential in the prediction of the total solar radiation on the inclined surface [24].

\section{Materials and Methods}

\subsection{Location}

The research project was carried out in the city of Juliaca, province of San Román department of Puno in Peru. Located in latitude south $15^{\circ} 29^{\prime} 27^{\prime \prime}$, longitude west $70^{\circ} 07^{\prime} 37^{\prime \prime}$ with an altitude of $3824 \mathrm{msnm}$.

\subsection{Materials}

To measure the Solar Irradiation, a portable MACSOLAR SLM018c-2 measuring instrument of German origin was used, a $100 \mathrm{w}$ mono crystalline solar photovoltaic module, a 140 liter solar vacuum tube thermometer, electric pump for hot water recirculation, PT-100 sensor, temperature controller and an experimental floor heating module.

\subsection{Methodology}

Data obtained from the Solar Irradiation measurement, during 3 months (July, August and September) of the year 2017 , every day from 6:00 am to 5:00 pm with an interval of 30 minutes between each data, considering the average 3month global to apply this Distribution method, we will determine if it has a Symmetric (Gaussian Bell) or Asymmetrical distribution:

For this we will use the Karl Pearson Coefficient method:

$$
A s=\frac{3(\bar{x}-M d)}{S}
$$

Where:

$\bar{x}=$ Arithmetic average

$\mathrm{Md}=$ Fashion

$\mathrm{S}=$ Standard deviation

Where the Pearson Coefficient is:

Note: The Pearson coefficient varies between -3 and 3 .

As $<0 \rightarrow$ The Distribution will be Negative Asymmetric.

As $=0 \rightarrow$ The distribution will be symmetric.

As $>0 \rightarrow$ The distribution will be positive asymmetric.

Then the Distribution is Negative Asymmetric.

We generate Table 1, to determine the Optima Frequency, in which the Solar Irradiation is equal to or greater than $1000 \mathrm{w} / \mathrm{m}^{2}$.

Table 1. Determination of the frequency of solar irradiation in the city of Juliaca.

\begin{tabular}{lll}
\hline Class & Cuts & Frequency \\
\hline 1 & 455.88 & 2 \\
2 & 619.42 & 0 \\
3 & 782.96 & 3 \\
4 & 946.5 & 3 \\
5 & 1110.04 & 15 \\
\hline
\end{tabular}

From Table 1, class 5 with a Solar Irradiation within the Cut of $1110.04 \mathrm{w} / \mathrm{m}^{2}$, there are 15 similar values, represented in time 14 half-hour intervals adding 7 hours of constant Solar Irradiation greater than $1000 \mathrm{w} / \mathrm{m}^{2}$. Showing the frequency in Figure 1, which looks like the Negative Asymmetric distribution. 


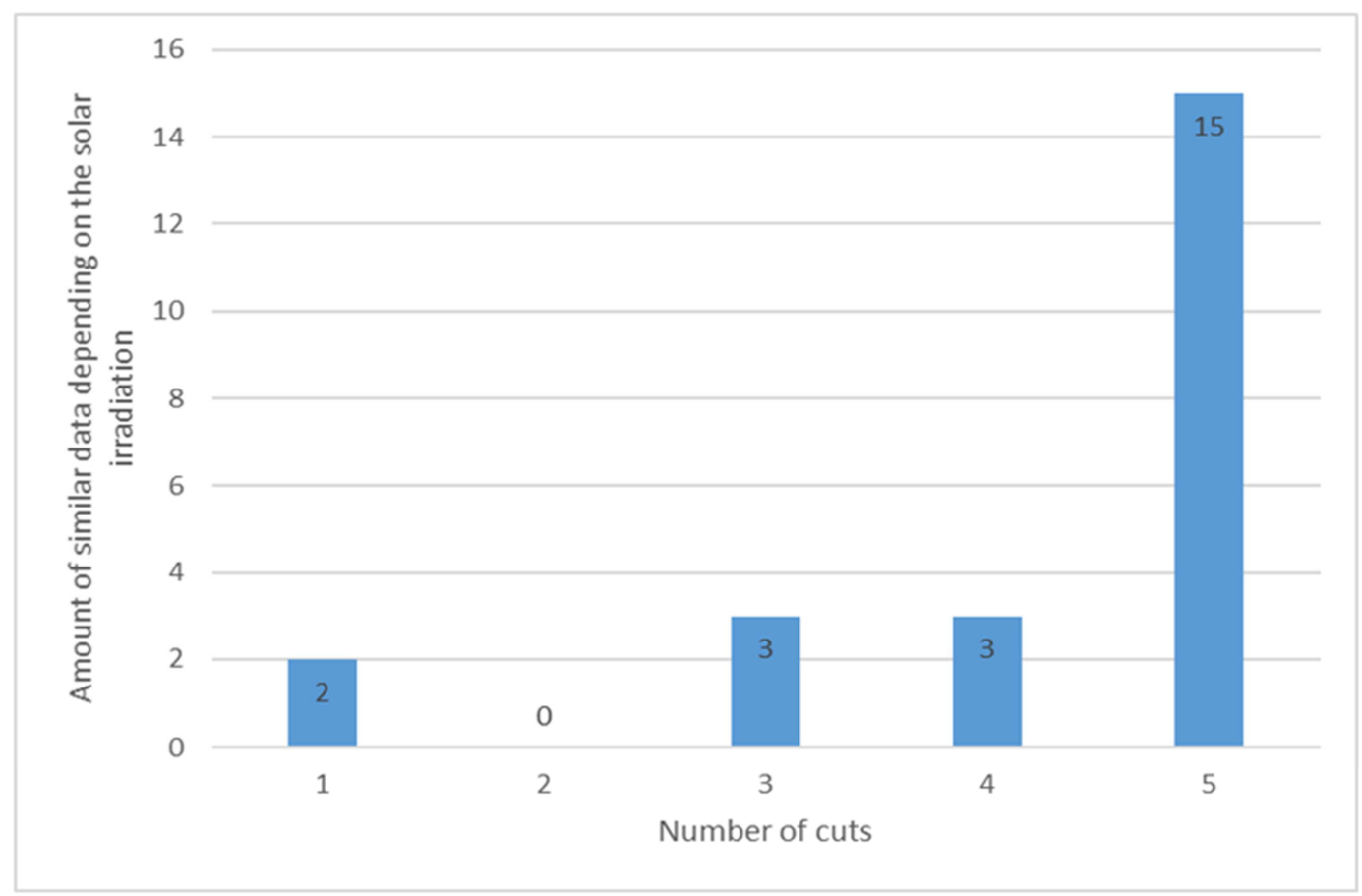

Figure 1. Frequency of Repetitions of Solar Radiation in the city of Juliaca.

Based on the Negative Asymmetric distribution, we will use Excel to determine this distribution:

$$
I S P=\operatorname{Min}+n_{i} \times \text { Incremento } 2
$$

Where:

IPS $=$ Average Solar Radiation $\left(\mathrm{w} / \mathrm{m}^{2}\right)$

$n_{i}=$ Data

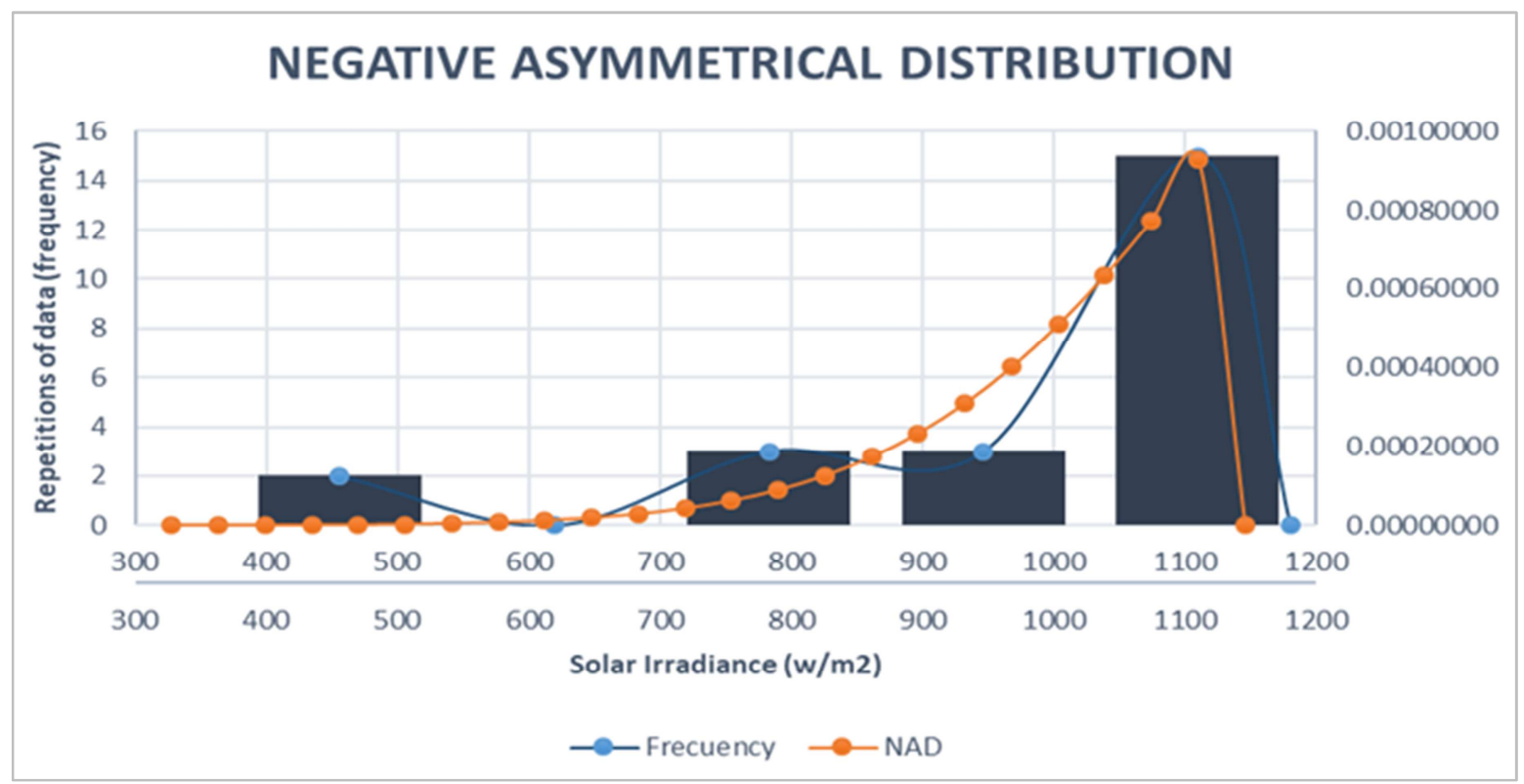

Figure 2. Approximation by Negative and Polynomial Asymmetric Distribution, comparing with Frequency.

Comparing Frequency Figure 1 with Figure 2 of Negative Asymmetric Distribution, it has a similar similarity with which this method approximates with the Negative Asymmetric Distribution.

From the result of the Negative Asymmetric Distribution of Figure 2, with figure 1 of frequencies, 15 data approximate the Solar Irradiation of $1110.04 \mathrm{w} / \mathrm{m}^{2}$ (15 points with time intervals of $30 \mathrm{~min}$ ). To determine the average global peak sun hours per day (HSP), of the 15 data they would have 14 intervals, equivalent to 7 hours. 


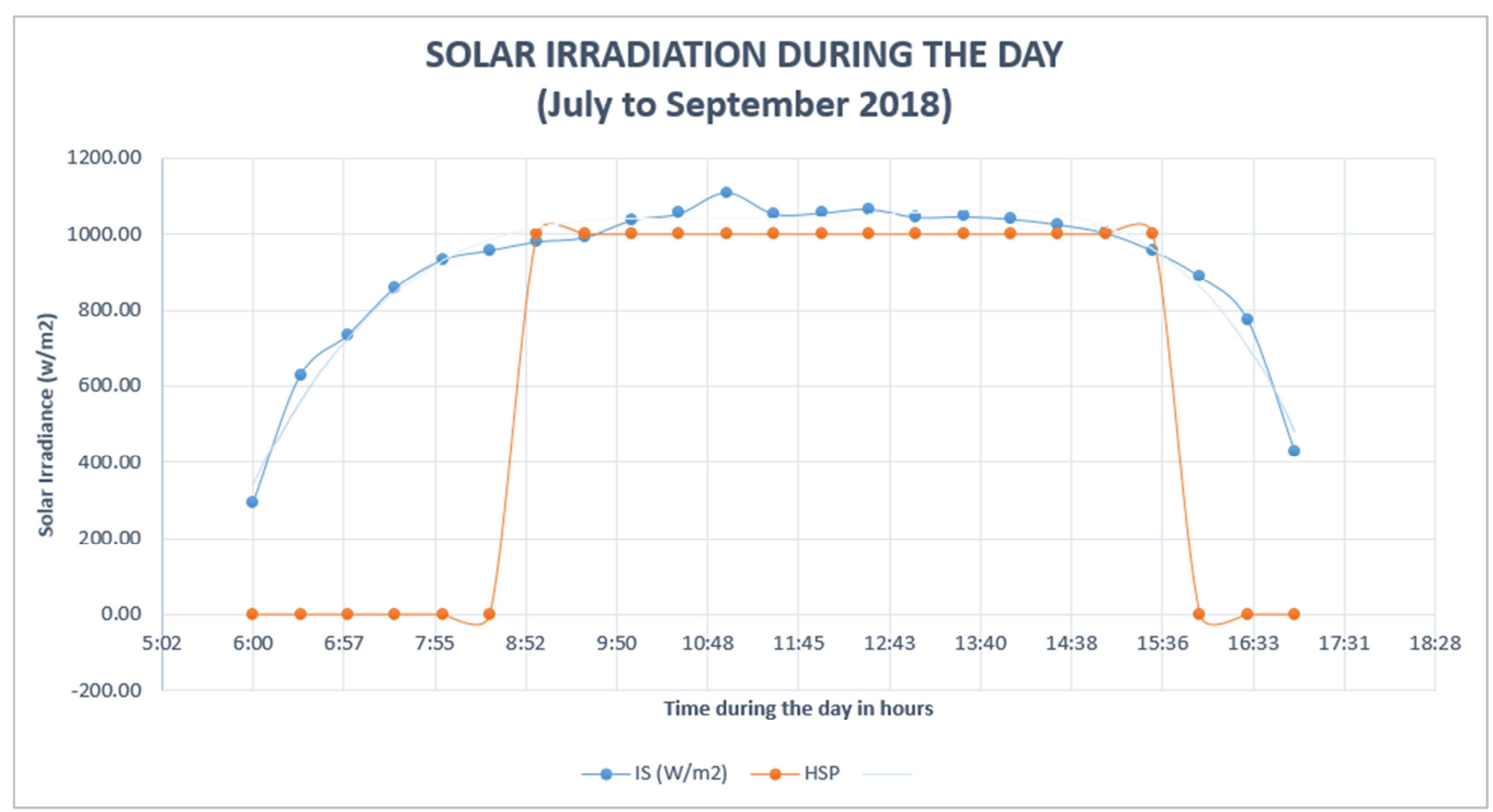

Figure 3. Average Solar Peak Time (HSP) in Juliaca from July to September 2017.

Figure 3 shows the Global Average Solar Irradiance in (HSP) of $6.623 \mathrm{kwh} / \mathrm{m}^{2} /$ day given in the day, taking as a working interval the time from 9:00 to 13:00 hours as observed in the figure.

\section{Results and Discussions}

\subsection{Results}

Using a Solar Irradiation measuring instrument (MACSOLAR Radiometer); where a maximum solar radiation of $1291 \mathrm{w} / \mathrm{m}^{2}$ was observed being 11:45 am in the city of Juliaca in the month of September of the year 2017 and an average solar irradiation of $1010.04 \mathrm{w} / \mathrm{m}^{2}$ between 9:00 a.m. 3:00 p.m., which is enough for a photovoltaic solar panel to work efficiently because the photovoltaic cells need a solar irradiation of $1000 \mathrm{w} / \mathrm{m}^{2}$.

In addition, based on the SENAMHI (National Service of Meteorology and Hydrology of Peru); the annual average solar incident solar energy of the years (1975 - 1990), observed in the city of Juliaca, showing the dark yellow zone in figure 4 with values between $(6-6.5) \mathrm{kwh} / \mathrm{m}^{2} /$ day; with solar irradiation higher than this value in the city of Juliaca de (HSP) $6.623 \mathrm{kwh} / \mathrm{m}^{2} /$ day.

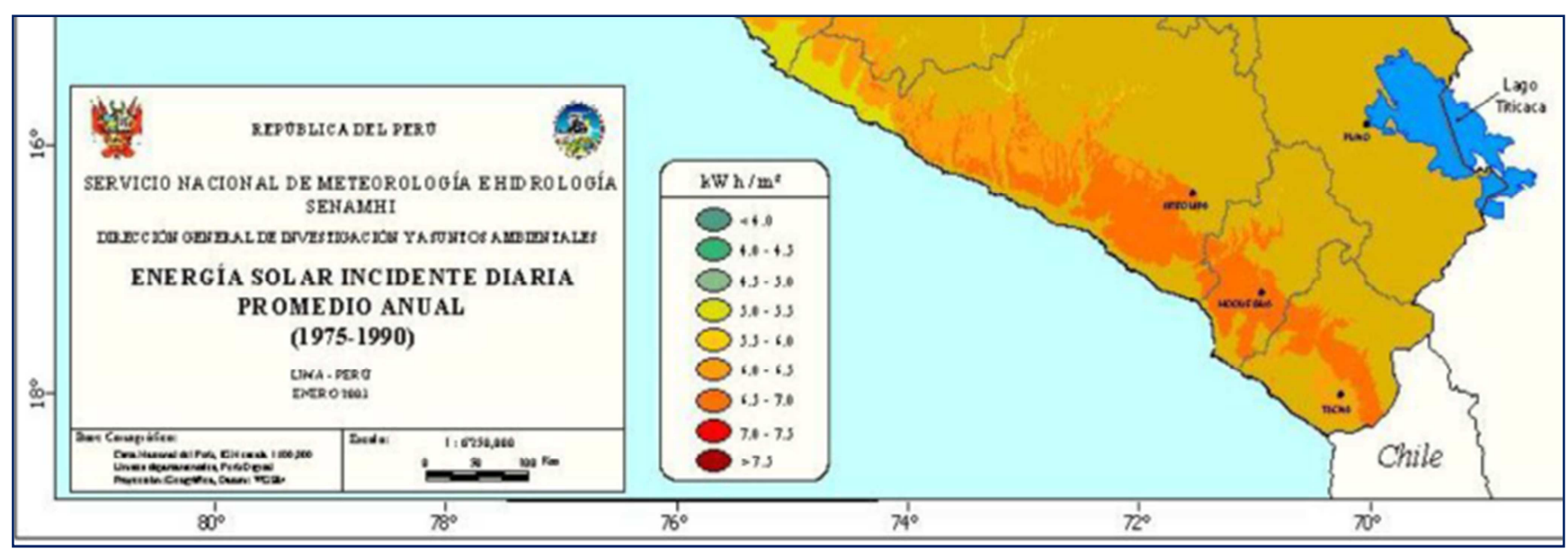

Figure 4. Solar Energy Annual Average Daily Incident [25].

Figure 3 shows the average irradiation of the three months expressed per day, considering the irradiation usable from 9:00 to $15: 00$ hours obtaining the (HSP) of solar energy of 6.623 $\mathrm{kwh} / \mathrm{m}^{2} /$ day, for the sizing of photovoltaic and thermal systems. 


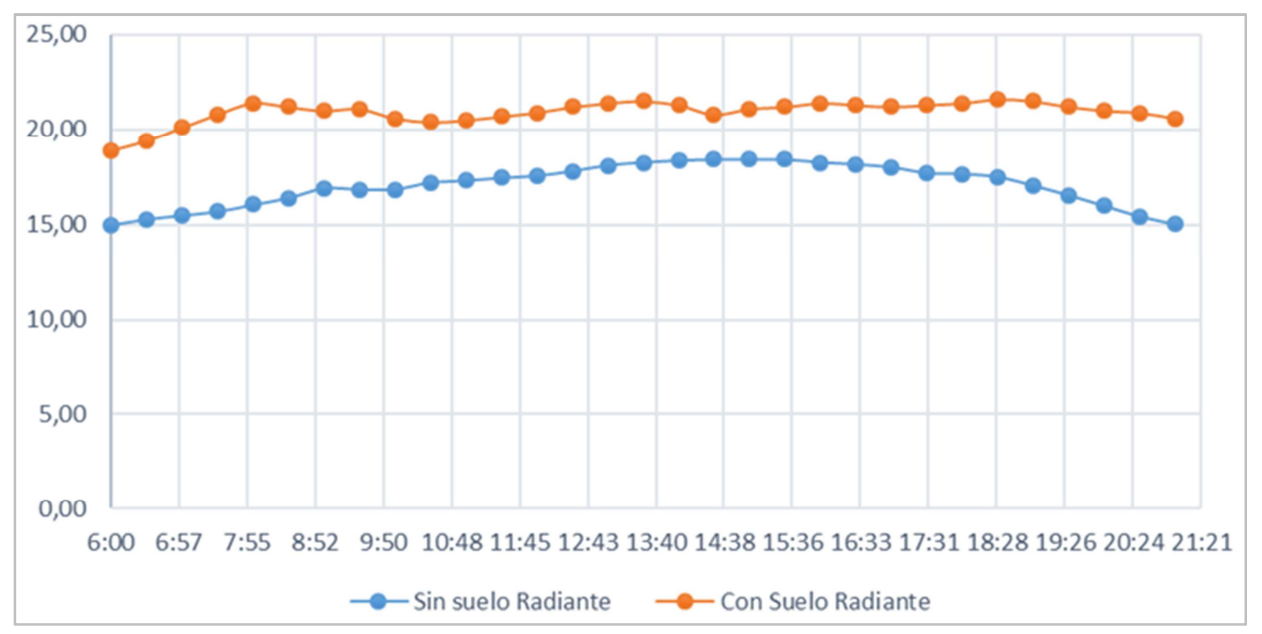

Figure 5. Behavior of the temperature with and without underfloor heating in Juliaca, December 2017.

Figure 5 shows the behavior of the temperature in the blue line without using a radiant floor for three days, averaging $17.07^{\circ} \mathrm{C}$ during the day. In addition you can observe the orange line where the behavior of the temperature is observed using radiant floor that is higher in approximately $(4-5)^{\circ} \mathrm{C}$ obtaining an average of $20.93^{\circ} \mathrm{C}$.

According to the (Peruvian Technical Standard) NTP N ${ }^{\circ}$ 501 of Thermal Environments, establishes the thermal comfort zone from $(17-27)^{\circ} \mathrm{C}$, in the experimental module an average of $20.93{ }^{\circ} \mathrm{C}$ was reached, being within the NTP. According to the Givoni diagram, a temperature comfort zone between $(20-27){ }^{\circ} \mathrm{C}$ is estimated, being within the comfort zone. Figure 6 shows the experimental design of Radiant Soil implemented in the city of Juliaca - Peru.

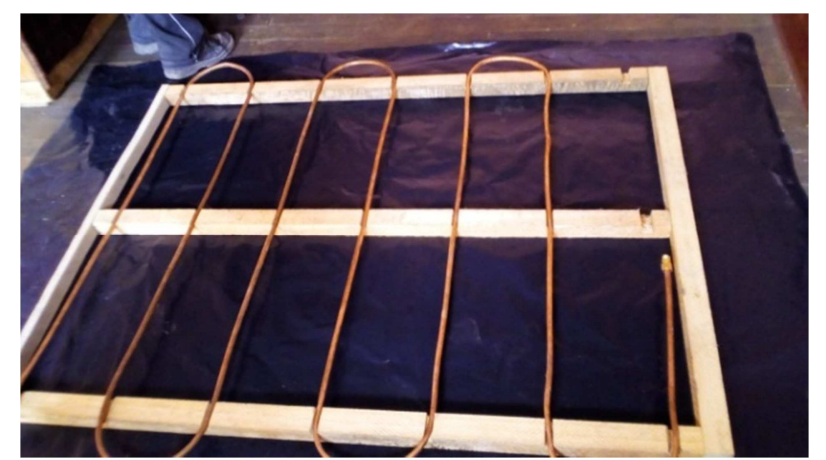

Figure 6. Radiant floor (Juliaca)

\subsection{Discussions}

In the study entitled "Performance Study of a DualFunction Thermosyphon Solar Heating System", performed by [26] to design solar thermal baths, the author considers in a 3-day evaluation a peak Solar Irradiation maximum of $830 \mathrm{w} / \mathrm{m}^{2}$ shown in figure 7 , which in the city of Juliaca shows a peak average Solar Irradiation of $1110.04 \mathrm{w} / \mathrm{m}^{2}$ measured in 3 months; In addition, the author in his research with the design of the Vacuum Tube Solar Collector achieved an efficiency of $73.68 \%$.

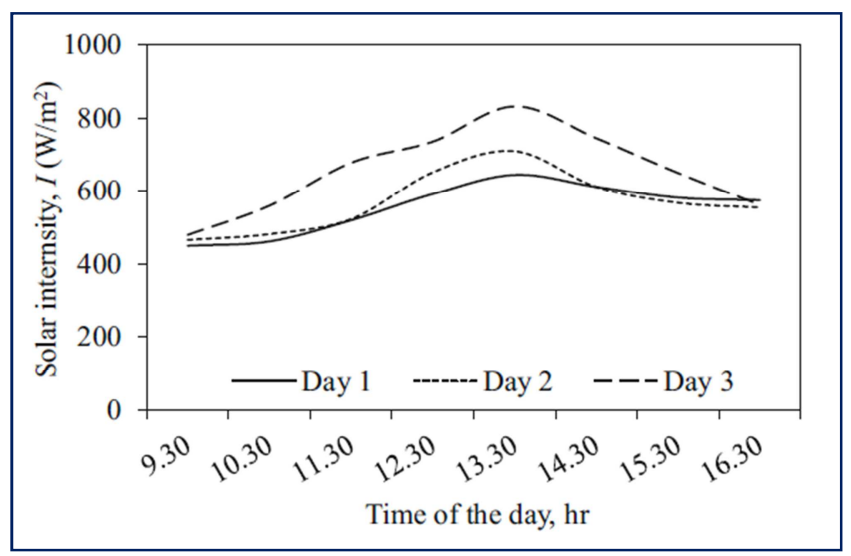

Figure 7. Variation of the daily Solar Incidence [26].

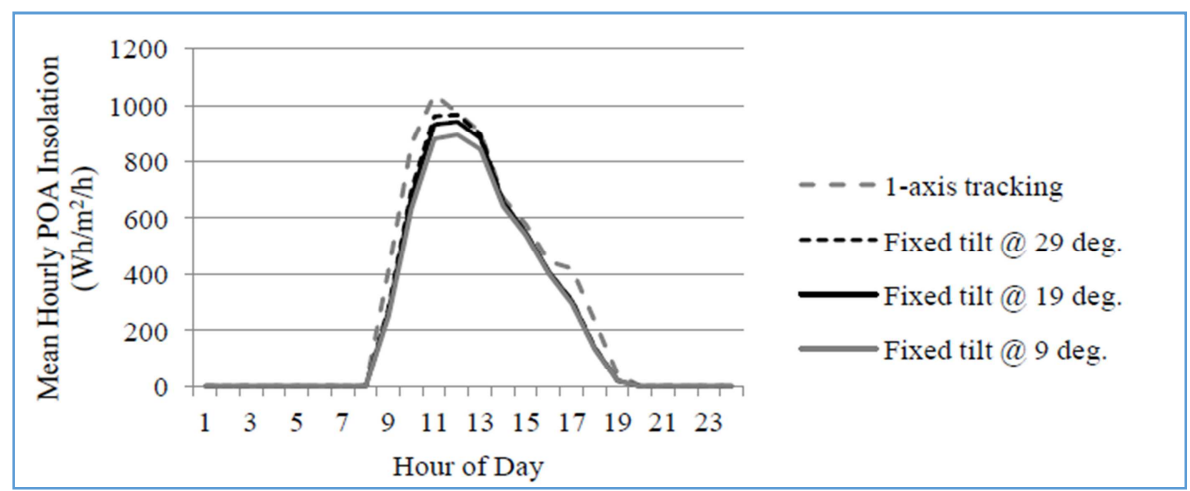

Figure 8. Daily insolation in the month of February 2015 [27]. 
Comparing another research done in Mumbai entitled "Impact of Solar Panel Orientation on Large Scale Rooftop Solar Photovoltaic Scenario for Mumbai", conducted by [27], makes a study of Solar Irradiation in the month of February 2015 noting that insolation solar starts from 8:00 and ends at 6:30 p.m., reaching the maximum point of 978 $\mathrm{w} / \mathrm{m}^{2}$, considering the area of (HSP) from 10:30 am to $1: 30$ p.m. where it is shown in figure 8 having a working range of 3 Hours; in the city of Juliaca an average working range of 6.5 hours is shown, showing more than double.
In the research entitled "Experimental implementation of meteorological data and photovoltaic solar radiation monitoring system" made by the author [28] where he conducted a study of the potential solar incidence of Russia by evaluating the Solar Radiation peak average per day of $812 \mathrm{w} / \mathrm{m}^{2}$ which does not reach $1000 \mathrm{w} / \mathrm{m} 2$ observed in figure 9 , in the city of Juliaca exceeds $1000 \mathrm{w} / \mathrm{m}^{2}$ in a time interval of 6.5 hours being a potential area for the use of Solar energy.

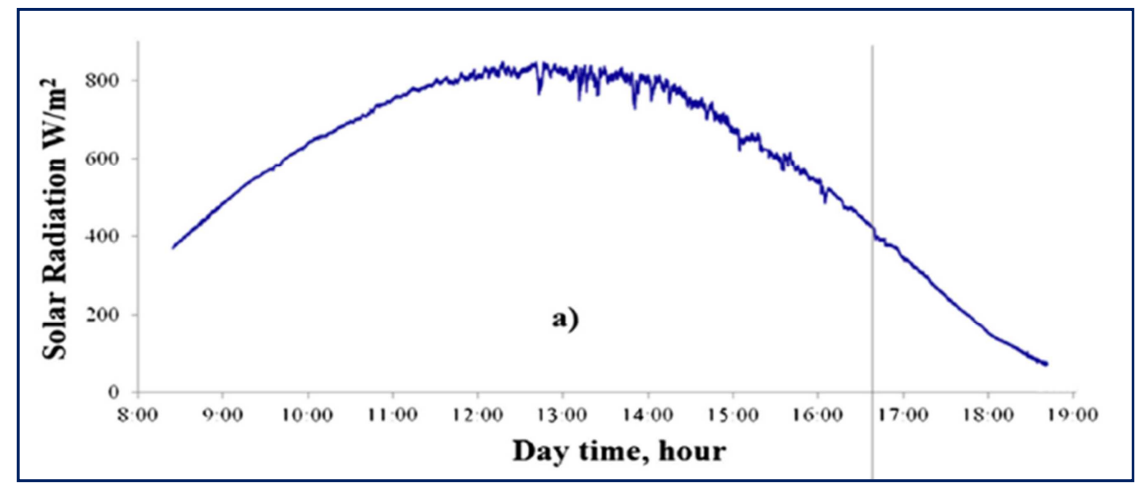

Figure 9. Solar radiation incident by the NOAA satellite [28].

A work entitled "Building integrated solar thermal systems presentation and zoom on the solar potential"[9], carried out in BIST (Barcelona Institute of Science and Technology) in a bioclimatic building with solar energy demonstrates that The peak Solar Irradiation in the month of August is $955 \mathrm{w} / \mathrm{m}^{2}$ with a symmetrical variation during the day, but in the month of December there is an increase to
$1098 \mathrm{w} / \mathrm{m}^{2}$ peak with an average of $1047 \mathrm{w} / \mathrm{m}^{2}$ in a range of very short time of $30 \mathrm{~min}$ of (HSP) shown in figure 10, which is very little to have a good performance with equipment that work with solar energy; what we mentioned above from the city of Juliaca has a peak average of 1110.04 $\mathrm{w} / \mathrm{m}^{2}$ and a time interval of 6.5 hours (HSP).

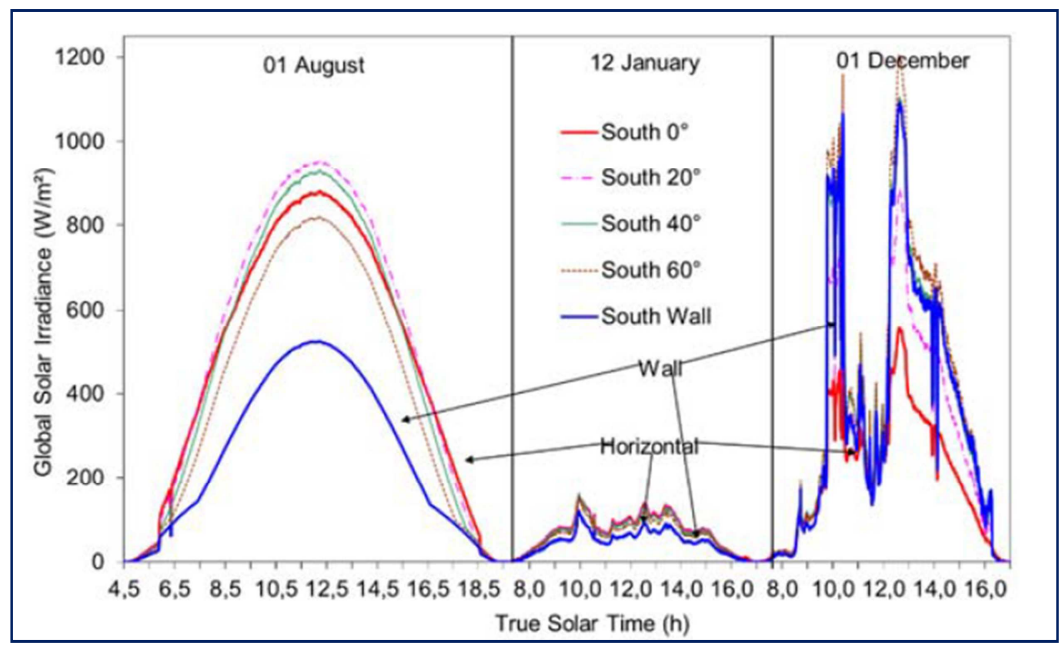

Figure 10. Influence by inclination for three days in Ajjacio [9].

In the scientific article entitled "Evaluation of downward currents of glass curtain wall buildings with a radiant floor heating system" [29], for this evaluation, a floor heating system was applied to the perimeter zones with different window types modeled using a Computational Fluid Dynamics (CFD) simulation with an initial temperature between $(10-16)^{\circ} \mathrm{C}$ for 24 hours. The results of the simulation show that the temperature difference between the air supplied through the underfloor heating system and the air descending along the cold surface of the window increased between $(18-20)^{\circ} \mathrm{C}$ shown in the Figure 11, comparing with the research carried out in the experimental room, an average temperature of $20.93^{\circ} \mathrm{C}$ is reached, demonstrating the increase in temperature thanks to the use 
of renewable solar energy.

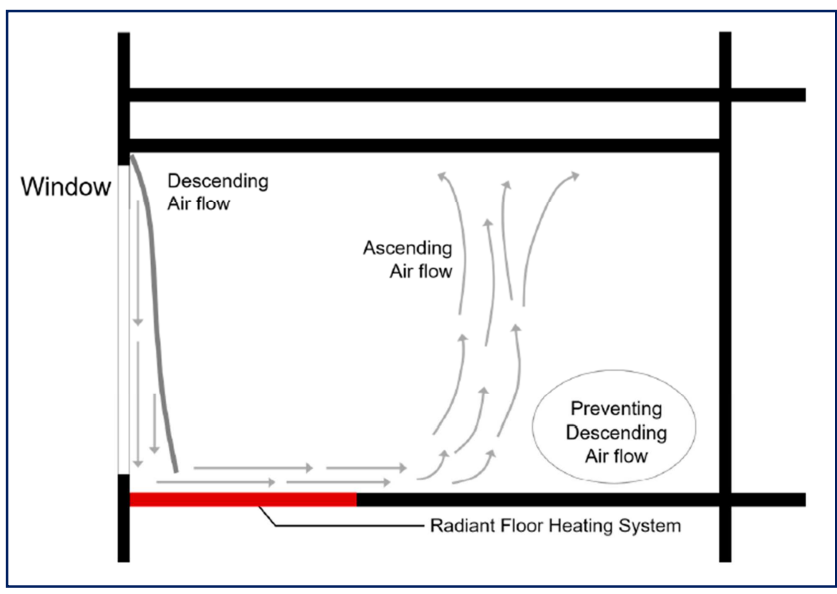

Figure 11. Air flow by application of RFHS [29].

In the research entitled "Experimental evaluation of the thermal performance of the radiant heating panels integrated in raised soil" [30], where they compare three types of radiant floor heating integrated to raised floors of different filling materials for the lower insulation of the panel obtaining for five hours temperatures between $(20-29){ }^{\circ} \mathrm{C}$ shown in figure 12, with which the radiant floor of this investigation reached values $(18.9-21.6){ }^{\circ} \mathrm{C}$ which would be within the comfort zone of [31] and of the NTP.

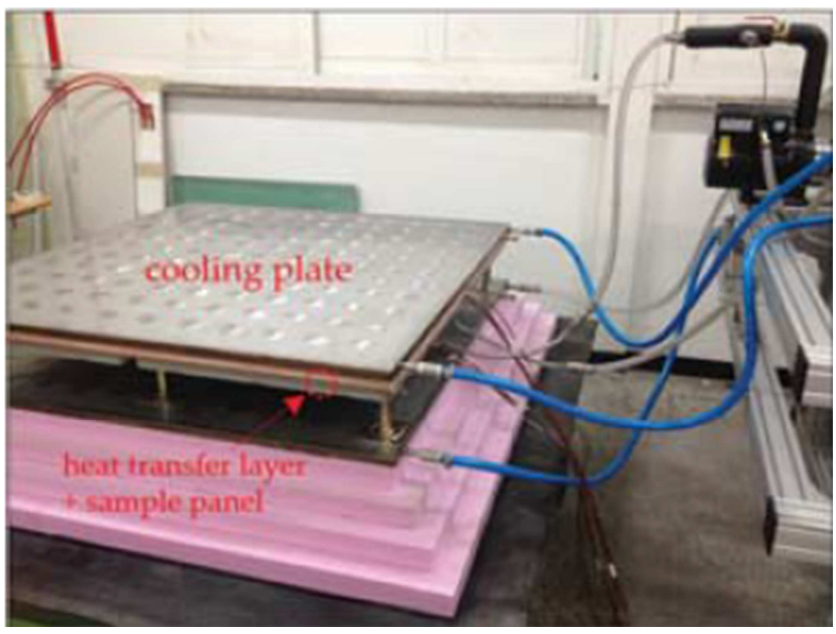

Figure 12. Experimental module of the radiant floor [30].

\section{Conclusions}

The variables of solar energy were determined, observing a global average solar irradiation on non-cloudy days without rain of $1110.04 \mathrm{w} / \mathrm{m}^{2}$ during 9:00 a.m. to 5:00 p.m., which is higher than the Standard Conditions of Measurement. (CEM) of $1000 \mathrm{w} / \mathrm{m}^{2}$. With this Solar Irradiation, photovoltaic and thermal systems work efficiently for the design of bioclimatic housing.

With the data obtained from the solar irradiation, the behavior of the solar energy expressed (HSP) of 6.623 $\mathrm{kwh} / \mathrm{m}^{2} /$ day was determined, with this result the photovoltaic and thermal system was designed in the city of Juliaca to implement an experimental module in a room using the radiant floor as a bioclimatic medium to obtain adequate comfort.

In the bioclimatic experimental module, analyzing the results with the temperature sensor installed at $60 \mathrm{~cm}$ height from 6:00 am to 9:00 pm, without using the radiant floor, the temperature in the environment is in the range of $(15-18.40)^{\circ} \mathrm{C}$ with an average of $17.07^{\circ} \mathrm{C}$ and when we use the radiant floor it is in the range of $(18.90-21.60)^{\circ} \mathrm{C}$ with an average of $20.93^{\circ} \mathrm{C}$ being inside the comfort zone by (NTP) $\mathrm{N}^{\circ} 501$ of $(17-27)^{\circ} \mathrm{C}$ and of the Psychometric diagram of Givoni.

\section{References}

[1] C. Bulei, M.-P. Todor, D. D. Cornea, and I. Kiss, "Solar Air Heating Collectors in two Modular Solar Panels Build Into A Do-It-Yourself Type Project using Photovoltaic Cells and Recycled Aluminum Cans," Acta Technica Corvininesis Bulletin of Engineering, vol. 10, pp. 44-49, 2017.

[2] C. Bertrand, C. Housmans, J. Leloux, and M. Journée, "Solar irradiation from the energy production of residential PV systems," Renewable Energy, vol. 125, pp. 306-318, 2018/09/01/ 2018.

[3] S. Pili, G. Desogus, and D. Melis, "A GIS tool for the calculation of solar irradiation on buildings at the urban scale, based on Italian standards," Energy and Buildings, vol. 158, pp. 629-646, 2018/01/01/2018.

[4] N. Sarmiento, S. Belmonte, P. Dellicompagni, J. Franco, K. Escalante, and J. Sarmiento, "A solar irradiation GIS as decision support tool for the Province of Salta, Argentina," Renewable Energy, vol. 132, pp. 68-80, 2019/03/01/ 2019.

[5] I. Majumder, P. K. Dash, and R. Bisoi, "Variational mode decomposition based low rank robust kernel extreme learning machine for solar irradiation forecasting," Energy Conversion and Management, vol. 171, pp. 787-806, 2018/09/01/2018.

[6] S. Motahhir, A. El Hammoumi, and A. El Ghzizal, "Photovoltaic system with quantitative comparative between an improved MPPT and existing INC and P\&O methods under fast varying of solar irradiation," Energy Reports, vol. 4, pp. 341-350, 2018/11/01/2018.

[7] I. Gašparović, M. Gašparović, and D. Medak, "Determining and analysing solar irradiation based on freely available data: A case study from Croatia," Environmental Development, vol. 26, pp. 55-67, 2018/06/01/2018.

[8] C. Voyant and G. Notton, "Solar irradiation nowcasting by stochastic persistence: A new parsimonious, simple and efficient forecasting tool," Renewable and Sustainable Energy Reviews, vol. 92, pp. 343-352, 2018/09/01/2018.

[9] G. Notton, "Building integrated solar thermal systems presentation and zoom on the solar potential," Romanian Journal of Civil Engineering / Revista Romana de Inginerie Civila, vol. 8, pp. 1-11, 03// 2017.

[10] S. Hands, S. Sethuvenkatraman, M. Peristy, D. Rowe, and S. White, "Performance analysis \&amp; energy benefits of a desiccant based solar assisted trigeneration system in a building," Renewable Energy, vol. 85, pp. 865-879, 1// 2016. 
[11] T. Gutiérrez, R. Romero, and C. Sotelo, "Thermal Energy Impact of Bioclimatic Techniques Applied to Low-income Housing in a Hot Dry Climate," Energy Procedia, vol. 57, pp. 1743-1752, 1/1/2014 2014.

[12] J. Ratanachotinun, N. Kasayapanand, J. Hirunlabh, S. Visitsak, S. Teekasap, and J. Khedari, "A design and assessment of solar chimney of bioclimatic house wall and roof for construction in the housing market of Thailand," Building Services Engineering Research \& Technology, vol. 37, pp. 694-709, 2016.

[13] D. L. Zr and S. Mochtar, "Application of Bioclimatic Parameter as Sustainability Approach on Multi-story Building Design in Tropical Area," Procedia Environmental Sciences, vol. 17, pp. 822-830, 1/1/2013 2013.

[14] E. De Angelis, L. C. Tagliabue, F. R. Cecconi, and A. G. Mainini, "A Simple Method for the Comparison of Bioclimatic Design Strategies Based on Dynamic Indoor Thermal Comfort Assessment for School Buildings," Procedia Engineering, vol. 180, pp. 870-880, 1/1/2017 2017.

[15] T. Hassboun, L. El Bahir, Y. Aite Driss, and M. El Adnani, "Solar irradiation estimator based on a self-calibrated reference solar cell," Turkish Journal of Electrical Engineering \& Computer Sciences, vol. 24, pp. 4885-4899, 2016.

[16] M. Hartner, A. Ortner, A. Hiesl, and R. Haas, "East to west The optimal tilt angle and orientation of photovoltaic panels from an electricity system perspective," Applied Energy, vol. 160, pp. 94-107, 12/15/2015.

[17] P. Si, Y. Lv, X. Liu, X. Rong, and Y. Feng, "An Optimization Model Applied to Active Solar Energy System for Buildings in Cold Plateau Area," Energy Procedia, vol. 88, pp. 443-449, 6/1/June 20162016.

[18] A. Carreño-Ortega, E. Galdeano-Gómez, J. C. Pérez-Mesa, and M. del Carmen Galera-Quiles, "Policy and Environmental Implications of Photovoltaic Systems in Farming in Southeast Spain: Can Greenhouses Reduce the Greenhouse Effect?," Energies (19961073), vol. 10, pp. 1-24, 2017.

[19] A. Girard, E. J. Gago, J. Ordoñez, and T. Muneer, "Spain's energy outlook: A review of PV potential and energy export," Renewable Energy, vol. 86, pp. 703-715, 2// 2016.

[20] R. Affandi, M. R. A. Ghani, C. K. Ghan, and L. G. Pheng, "The Impact of the Solar Irradiation, Collector and the Receiver to the Receiver Losses in Parabolic Dish System,"
Procedia - Social and Behavioral Sciences, vol. 195, pp. 2382-2390, 7/3/3 July 20152015.

[21] R. A. Suárez, G. Abal, P. Musé, and R. Siri, "Satellite-derived Solar Irradiation Map for Uruguay," Energy Procedia, vol. 57, pp. 1237-1246, 1/1/2014 2014.

[22] Y. Matsumoto, M. Valdés, J. A. Urbano, T. Kobayashi, G. López, and R. Peña, "Global Solar Irradiation in North Mexico City and Some Comparisons with the South," Energy Procedia, vol. 57, pp. 1179-1188, 1/1/2014 2014.

[23] L. Jiandong, P. Tao, C. Deliang, Z. Xiuji, Y. Qiang, G. N. Flerchinger, et al., "An Improved Ångström-Type Model for Estimating Solar Radiation over the Tibetan Plateau," Energies (19961073), vol. 10, pp. 1-28, 2017.

[24] E. Kiplangat Ronoh, "Prediction of total solar irradiance on tilted greenhouse surfaces," Agricultural Engineering International: CIGR Journal, vol. 19, pp. 114-121, 2017.

[25] SENAMHI, "Parametros Climatologicos Promedio en Juliaca," ed, 2017.

[26] K. Velmurugan, W. Christraj, N. Kulasekharan, and T. Elango, "Performance Study of a Dual-Function Thermosyphon Solar Heating System," Arabian Journal for Science \& Engineering (Springer Science \& Business Media B.V.), vol. 41, pp. 1835-1846, 2016.

[27] R. Singh and R. Banerjee, "Impact of Solar Panel Orientation on Large Scale Rooftop Solar Photovoltaic Scenario for Mumbai," Energy Procedia, vol. 90, pp. 401-411, 12/1/December 20162016.

[28] H. Rezk, I. Tyukhov, and A. Raupov, "Experimental implementation of meteorological data and photovoltaic solar radiation monitoring system," International Transactions on Electrical Energy Systems, vol. 25, pp. 3573-3585, 2015.

[29] L. Goosang Joe, A. Dongwoo Kim, O. Sanghoon Park, S. Sojeong Park, M. Myoungsouk Yeo, and S. Kwangwoo Kim, "Downdraft Assessment of Glass Curtain Wall Buildings with a Radiant Floor Heating System," Applied Sciences (20763417), vol. 7, pp. 1-23, 10// 2017.

[30] K. Dong-Woo, J. Goo-Sang, P. Sang-Hoon, Y. Myoung-Souk, and K. Kwang-Woo, "Experimental Evaluation of the Thermal Performance of Raised Floor Integrated Radiant Heating Panels," Energies (19961073), vol. 10, pp. 1-18, 2017.

[31] B. Givoni, Man, Climate and Architecture. New York: EEUU, 1969. 